\title{
Primary Lung Sarcoma Mimicking Left Atrial Myxoma
}

\author{
Amitabh Satsangi* \\ Resident, Department of Cardiothoracic and Vascular Surgery, All India Institute of Medical Sciences, India
}

\begin{abstract}
A 32-years female was referred for surgery for Left atrial myxoma based on symptoms of dyspnea on exertion, palpitations and echocardiography revealing a left atrial mass, mostly likely a left atrial myxoma. On chest X-ray, there was right lower lobe white out which instigated the need to perform a CT chest. On CT Chest a $10.9 \times 14.2 \times 13.6 \mathrm{~cm}(\mathrm{AP} \times \mathrm{TR} \times \mathrm{CC}$ ) $\mathrm{cm}$ heterogenously hypodense mass was seen along the posterior and inferior aspect of right hemi thorax. It showed multiple vascular channels within it and broad base towards posterior pleura. It had ill defined planes with left atrium and extension into the left atrium through right inferior pulmonary vein. It was causing compression of right descending pulmonary artery and right lower lobe bronchus with collapse of right lower lobe. Likey etiology was sarcomatous/ malignant vascular mass. Patient was transferred to oncology department for further management.
\end{abstract}

\section{Keywords}

Left atrial myxoma, Pulmonary sarcoma, Primary lung tumor entering heart

\section{Introduction}

Myxomas are the most common primary cardiac tumor [1]. More than $75 \%$ of myxomas originate in the left atrium either at the mitral annulus or the fossa ovalis border of the interatrial septum and about $20 \%$ arise from the right atrium [2]. Primary pulmonary tumors presenting as cardiac masses are rare.

Here we present a case of primary pulmonary mass mimicking a left atrial myxoma.

\section{Case Summary}

A 32-years female was referred for surgery for Left atrial myxoma based on symptoms of dyspnea on exertion, palpitations and echocardiography revealing a left atrial mass, mostly likely a left atrial myxoma. On chest X-ray, there was right lower lobe white out which instigated the need to perform a CT chest (Figure 1 and Figure 2). On CT Chest a $10.9 \times 14.2 \times$ $13.6 \mathrm{~cm}(\mathrm{AP} \times \mathrm{TR} \times \mathrm{CC}) \mathrm{cm}$ heterogenously hypodense mass was seen along the posterior and inferior aspect of right hemi thorax. It showed multiple vascular channels within it and broad base towards posterior pleura. It had ill defined planes with left atrium and extension into the left atrium through right inferior pulmonary vein (Figure 3). It was causing compression of right descending pulmonary artery and right lower lobe bronchus with collapse of right lower lobe. Likey etiology was sarcomatous/malignant vascular mass. Patient was transferred to oncology department for further management.

\section{Discussion}

Metastatization of pulmonary neoplasm to the left atrium has been well documented, particularly in patients with primary lung cancer $[3,4]$.

In a previous review of 215 lung cancer patients studied by gadolinium-enhanced 3D magnetic resonance angiography, an involvement of the proximal portion of the pulmonary veins and an extension into the left atrium were found in $9(4.2 \%)$ and $2(0.9 \%)$ patients, respectively [5].

LA invasion usually occurs by two main mechanisms, including direct infiltration of myocardial tissue by contiguity and extension into the left atrium via the lymphatics and/or the pulmonary veins [6].

In our case there was direct extension of the pulmonary mass via the pulmonary veins into the left atrium in a contiguous manner. Our patient was initially diagnosed as a case of left atrial mass, thought to be a left atrial myxoma based upon symptoms of dyspneas on exertion and palpitation along with echo cardio graphic examination revealing a left atrial mass.

Since left atrial myxomas are the most common cardiac masses they were kept as an obvious differential diagnosis.

\footnotetext{
*Corresponding author: Amitabh Satsangi, MS, (Gen Surgery), Resident, Department of Cardiothoracic and vascular surgery All India Institute of Medical Sciences, New Delhi 10029, India

Accepted: December 29, 2020

Published online: December 31, 2020

Citation: Satsangi A (2020) Primary Lung Sarcoma Mimicking Left Atrial Myxoma. J Cardiothorac Surg Ther 4(1):72-74
} 


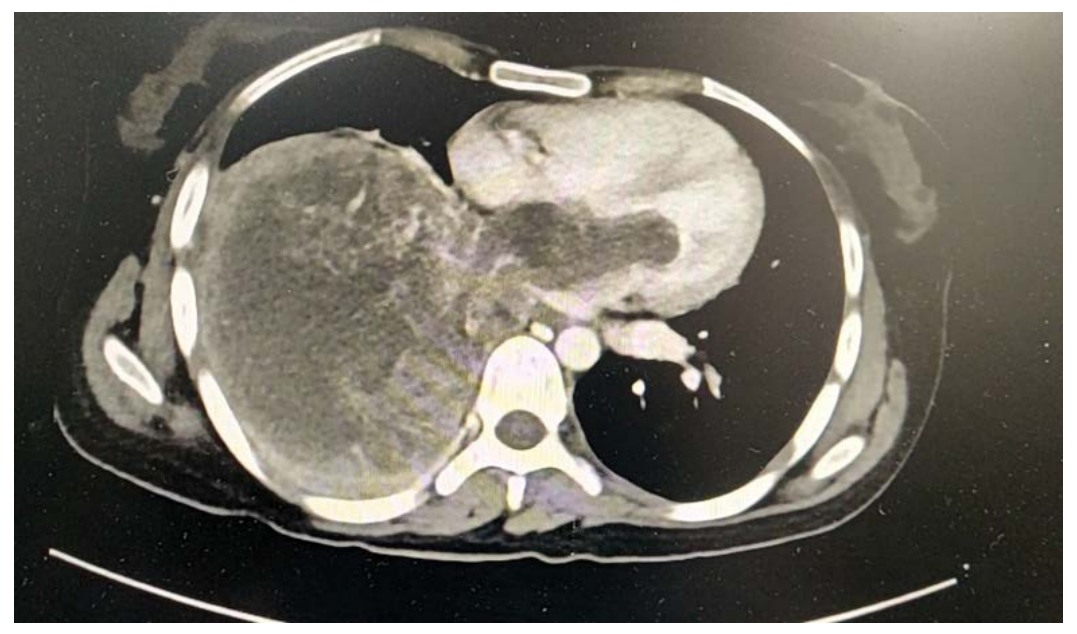

Figure 1: CT CHEST image showing right lung lower lobe mass and left atrial mass mimicking a left atrial myxoma.

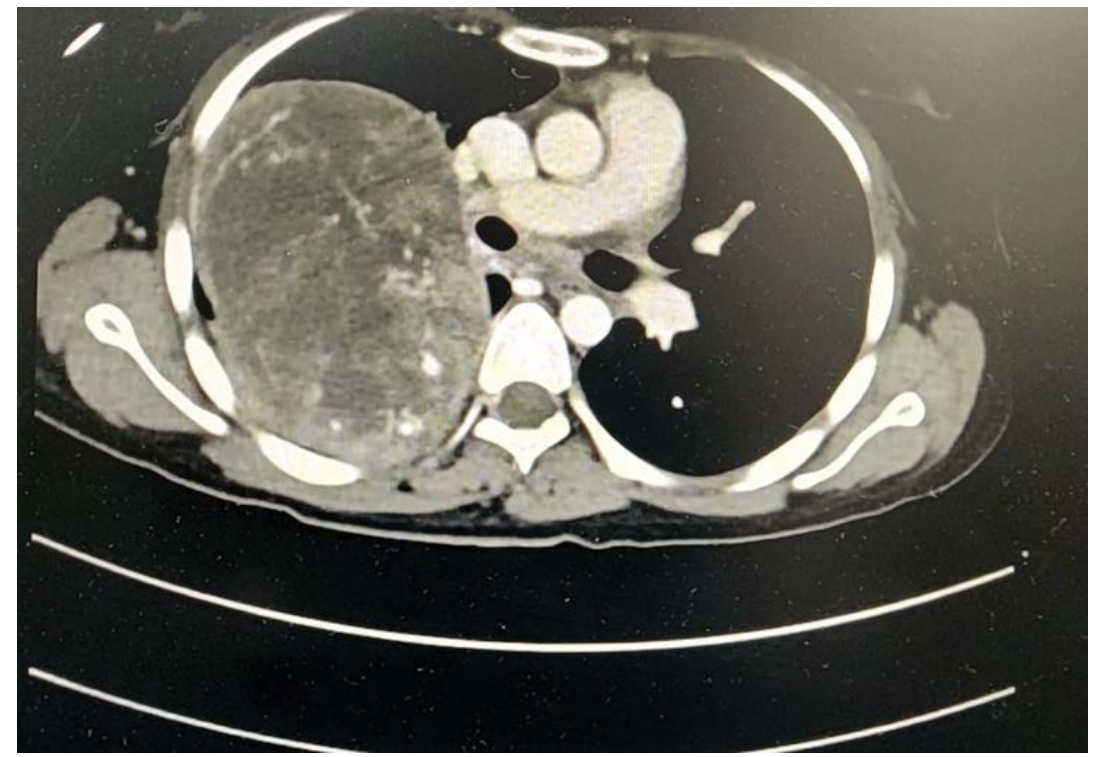

Figure 2: CT CHEST image showing right lung lower lobe mass.

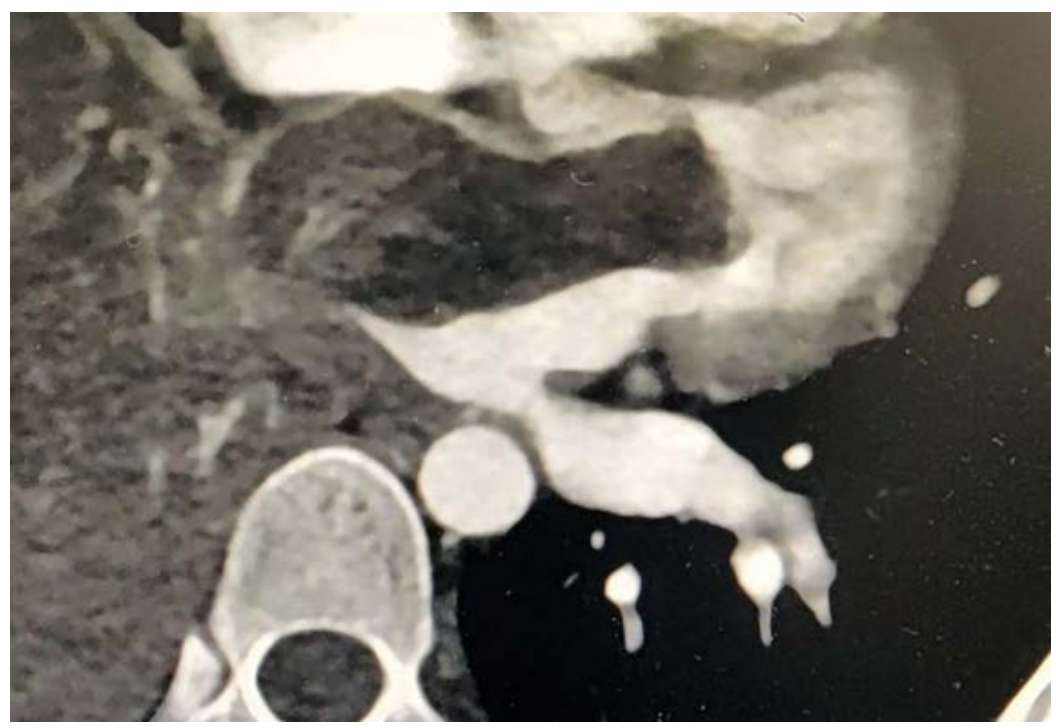

Figure 3: СT Chest image showing right lung lower lobe mass entering the left atrium through pulmonary vein. 
Our case deals with a diagnostic dilemma that can occur in a patient with cardiac mass and the importance of keeping primary pulmonary tumors as one of the cause of left atrial mass.

\section{References}

1. Ha JW, Kang WC, Chung N, et al. (1999) Echocardiographic and morphologic characteristics of left atrial myxoma and their relation to systemic embolism. Am J Cardiol 83: 1579-1582.

2. Jelic J, Milicić D, Alfirević I, et al. (1996) Cardiac myxoma: Diagnostic approach, surgical treatment and follow-up. A twenty years experience. J Cardiovasc Surg (Torino) 37: 113-117.

3. Chuah KL, Yap WM, Loh HL, et al. (2006) Intravenous extension of sarcomatoid carcinoma of the lung to the left atrium. Pathology (Phila) 38: 359-361.

4. Stella F, Dell'Amore A, Caroli G, et al. (2012) Surgical results and long-term follow-up of T4-non-small cell lung cancer invading the left atrium or the intrapericardial base of the pulmonary veins. Interact Cardiovasc Thorac Surg 14: 415-419.

5. Takahashi K, Furuse M, Hanaoka H, et al. (2000) Pulmonary vein and left atrial invasion by lung cancer: assessment by breathhold gadolinium-enhanced three-dimensional MR angiography. J Comput Assist Tomogr 24: 557-561.

6. Shimizu J, Ikeda C, Arano Y, et al. (2010) Advanced lung cancer invading the left atrium, treated with pneumonectomy combined with left atrium resection under cardiopulmonary bypass. Ann Thorac Cardiovasc Surg 16: 286-290.

DOI: $10.36959 / 582 / 428$

Copyright: (c) 2020 Satsang Ai. This is an open-access article distributed under the terms of the Creative Commons Attribution License, which permits unrestricted use, distribution, and reproduction in any medium, provided the original author and source are credited. 